\title{
China's New Directives on Nutraceuticals and Hong Kong Experience
}

\author{
Ping-Chung LEUNG ${ }^{1,2}$
}

\author{
${ }^{1}$ Institute of Chinese Medicine, the Chinese University of Hong \\ Kong, Hong Kong
}

${ }^{2}$ State Key Laboratory of Research on Bioactivities and Clinical Applications of Medicinal Plants (The Chinese University of Hong Kong), The Chinese University of Hong Kong, Hong Kong

\author{
Corresponding author \\ Ping-Chung LEUNG, 5/F School of Public Health Building, Prince of Wales \\ Hospital, Shatin, Hong Kong; Tel: (852) 22528868 Fax: (852) 2632 5441; \\ E-mail: pingcleung@cuhk.edu.hk
}

Submitted: 25 Feb 2019; Accepted: 07 Mar 2019; Published: 15 Mar 2019

\begin{abstract}
Nutraceuticals could be food or health supplements with vaguely described functional value. Inspite of the obvious uncertain health benefits, consumers maintain a blind trust. With the rising concern of healthy aging because of the explosion of the elderly population, health supplements have become ever popular.
\end{abstract}

In Asia, Traditional Herbal Medicine is commonly used in nutraceuticals and China must be one of the greatest producers.

Since 2015, the China FDA has issued a series of recommendations for the production of nutraceuticals which have been granted a new unique description of "Food Supplements with specific clinical use", and instructions on their production and evaluation are subsequently given. Clinical trials with the evidence-based principles are definite requirements.

Evidence-based production of nutraceuticals with specific clinical indications would follow the standard procedures of quality control; biological and pharmacological evaluation; followed by the provision of clinical evidences.

Hong Kong has been following such directions of developing health supplements. Brief descriptions will be given followed with the example of a cardiovascular tonic.

With such clear change of policy on the production of health supplements which is also in line with the recommendations of the European Union, one could expect a continuous supply of efficacious neuronenticals which could be registered for marketing as proprietary drug or health nutraceutical.

\section{Introduction}

Affluence is the direct force leading to the increasing concern about Health [1]. With the rising aging population, health concern is becoming even more real [2]. Concerned people, apart from getting proper medical advice, commonly look for dietary supplements which are labeled as health promoting agents useful to diseases [3]. Although many special terms have been used in the relevant labels of the dietary supplements viz. "Nutritives", "Supplements", "Herbals", "Nutraceuticals" etc., they commonly refer to the special product that is believed to promote health. "Nutraceuticals" is a term that is relatively new but apparently, does carry the closest reference to the product, since "Neutra" dissociates itself from specific aims whereas "ceuticals" refers clearly to treatment type of consumption. "Nutraceuticals", henceforth, will be the selected terminology in this communication, and the discussion will be focused on the use of medicinal herbs which are the major components of Traditional Chinese Medicine that remains popular ever since over 2000 years ago among the Chinese Communities [4]. Indeed hundreds of medicinal herbs have been selected as components of nutraceuticals.
Traditional Use of Medicinal Herbs

Medicinal herbs have been popular resources in the wild chase of specific target lead chemical molecules in Drug Discovery in the Pharmaceutical Industries [5]. One recent successful story that has earned a Nobel Recognition is Artemisinin developed from Herba Artemisia. Numerous other medicinal herbs traditionally used in complex herbal formulations, on the other hand, are applied in the day to day practice of Traditional Chinese Medicine doctors who whole-heartedly adore traditional experiences, records and classical authorities. Health market experts are aware of the rich collection of medicinal herbs and the general trusts among ordinary people about their health value. Hence combinations of medicinal herbs, in the form of cumbersome formulae or modified simple amalgamations are produced as nutraceuticals. Such products have appeared in markets as "proprietary medicine" or "nutraceuticals". The differentiation is mainly determined through the processes of commercial registration, not the real substance of the product.

"Kampo medicine" in Japan is composed of over 200 classic 
formulations in Traditional Chinese Medicine, registered as Proprietary Medicine, which could be prescribed by hospital practitioners or freely used by customers for a variety of health purposes [6]. Korea likewise is making full use of the Traditional Chinese Formulations under the broad category of "Oriental Medicine" [6].

On a very limited scale pharmacology experts have been making attempts to put specific Traditional Chinese Medicine formula onto standard drug manufacturing platforms along a pathway similar to the development of a new drug for specific purpose [7]. At this stage and along such pathway, one topical herbal agent for skin wart and one oral herbal supplement for diarrhea have been approved by the FDA of USA and one single herb oral nutraceutical for skeletal pain has been approved for marketing in the United Kingdom [8-10].

\section{Current Use of Medicinal Herbs}

The most popular use of Medicinal Herbs remains in the area of nutraceuticals registered under the category of "Food Supplements" or "Functional Food". Although not confined to Asia, herb containing nutraceuticals remain best known and most popular in China, Japan, Korea, India and South-East Asia. And India's historical inclination on the use of herbs could also be part of the historical influence received from the Middle East.

In China, nutraceuticals are created for common ailments and health promotion. The choice of herbs all depends on traditional believes and past experiences. Research to justify the claims is hardly considered. There is little worry about the mode of action, not to speak about, clinical evidences, the investment on which is beyond manufacturer's ability. On the other hand, traditional brand name, packaging and appropriate advertising will ensure a good return of profits.

The rising concern about health and a deep rooted classical belief in Traditional Medicine about preventing oneself from falling sick (which is more proactive than the prevention of diseases in modern Public Health concepts), are changing the overall perspectives and expectations on nutraceuticals.

\section{China's New Directives}

In 2015, the FDA of Chinaissued an "Instructional Guideline on the registration and control of Herbal Supplements with specific medical indication". In 2016, the guideline was followed by instructions on their production and evaluation $[11,12]$.

In 2017 Instructions for related Clinical Trials for the Herbal Supplements with specific medical indications were given [13].

Instead of following the old practice of accepting health supplements of general health support, the current Directives emphasize on specific medical indications. Moreover, clinical trial, which has never been a component of food supplements (nutraceuticals) is clearly spelled out.

Within a year, academics have responded quickly in the provision of research procedures to be taken in related evidence-based clinical trials, which are quite similar to procedures required for drug development. It has also been stated that priorities of provision of the nutraceuticals with specific medical purposes are given to babies, toddlers, lactating mothers and elderly people [14].
These New Directives are in-line with the China National Policy of "Healthy China 2030" which needs to be served by all professionals, particularly those belonging to the Health and Medical Category. Once followed, new production of nutraceuticals will be required to follow the Evidence-based direction, including clinical trials [11].

\section{Hong Kong Experience}

Hong Kong is a small city with well-known achievements on activities related to Finance and Commerce. It has hardly any ability related to pharmaceutical productions. However, being part of China and stationed in South China which has communities most loyal to herbal supplements, Hong Kong could take an academic lead on the development of Evidence-based nutraceuticals with specific medical indications.

Indeed, in the past twenty years, we have already followed an evidence based pathway, on the development of nutraceutical products to support clinical practices under various specialties in the hospital [15-17]. The following diagram outlines the principles of development.

\section{General Principles}

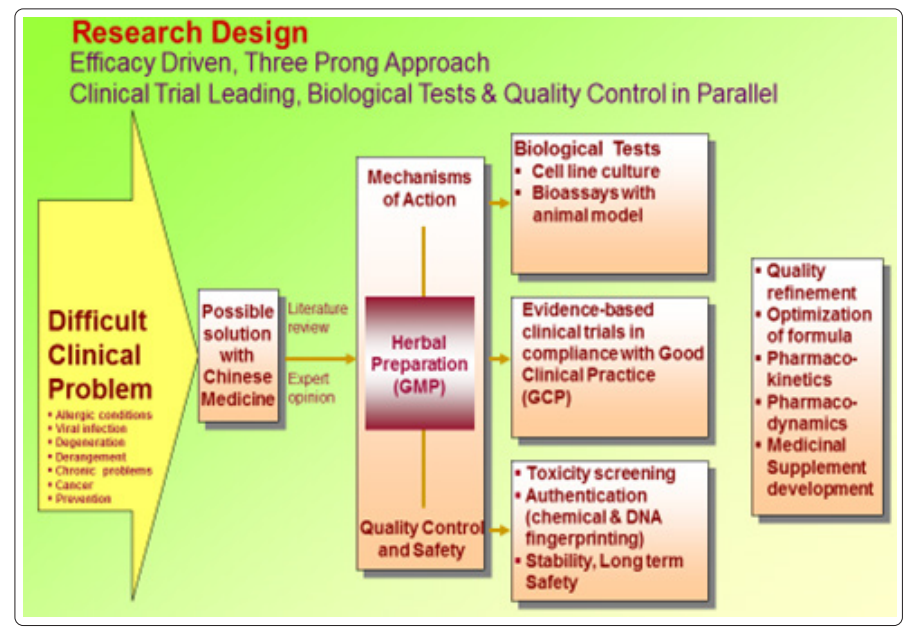

The comprehensive involvements require the participation of clinicians, herbalists, phytochemists, biochemists, and pharmacologists at different stages of development. The selection of medicinal herbs depends on the pathological activities known to be the causes of the clinical problems. Classic records about the herbs and modern biological platform research results will give the appropriate choice. For safety reasons and quality control, animal (or inserts) products and mineral compounds described and used in Traditional Chinese Medicine, would not be selected [18].

\section{One Example}

Cardiovascular health is a major problem among the aging population. Specific nutraceuticals to maintain vascular integrity would be very much desired, particularly before proper intervention (like specific medication or surgical procedures) is required, or, after proper intervention, responses are unsatisfactory.

We created an innovative cardiac tonic involving only two edible herbs viz. Salvia and Puerariae which were selected from a large group of herbs classically used for cardiovascular protection. The twin formula was put under experimental platforms to clarify its bioactivities, including anti oxidation; anti inflammation; cardio 
protection; angiogenic effects and related molecular pathways [19-22]. The formula was used in four clinical trials viz. coronary patients; diabetic and hypertensive patients; menopausal women; and people with peripheral vascular diseases. Standard serogate markers viz. carotid artery intimal thickness and brachial artery relaxation (ultrasonic measurements) have given reliable data to show the efficacy [18, 23-25].

The lengthy process of creating this evidence-based cardiovascular tonic could be represented by the following table.

\section{Table: A Nutraceutical with Specific Medical Purpose}

\begin{tabular}{|c|c|}
\hline Specific Medical Purpose & Cardiovascular Protection \\
\hline Choice of Herbs & $\begin{array}{c}\text { Widely used Salvia and } \\
\text { Innovative Puerariae }\end{array}$ \\
\hline Safety & Absolute \\
\hline Experimental Evidence & $\begin{array}{c}\text { Anti-oxidation; Anti } \\
\text { inflammation; Proangiogenic; } \\
\text { Vascular relaxation }\end{array}$ \\
\hline $\begin{array}{c}\text { Clinical Evidence: Serogate } \\
\text { markers (carotid intimal thickness } \\
\text { and Brachial artery relaxation), } \\
\text { QoL and others }\end{array}$ & $\begin{array}{c}\text { Four trials: Coronary disease; } \\
\text { Diabetic Hypertensives; } \\
\text { Menopausals; Peripheral vascular } \\
\text { disease patients }\end{array}$ \\
\hline Registration & As ProprietaryDrug \\
OR Food Supplement
\end{tabular}

\section{Discussion}

In 2010, a special committee in the European Union recommended that scientific evidences must be provided when a certain health claim is to be made by a Health Supplement Provider. The evidences could be simplified as: (i) proven absorbability (ii) components absorbed; (iii) subsequent physiological effects in the body; and (iv) proven efficacy on specific problems, including disease prevention.

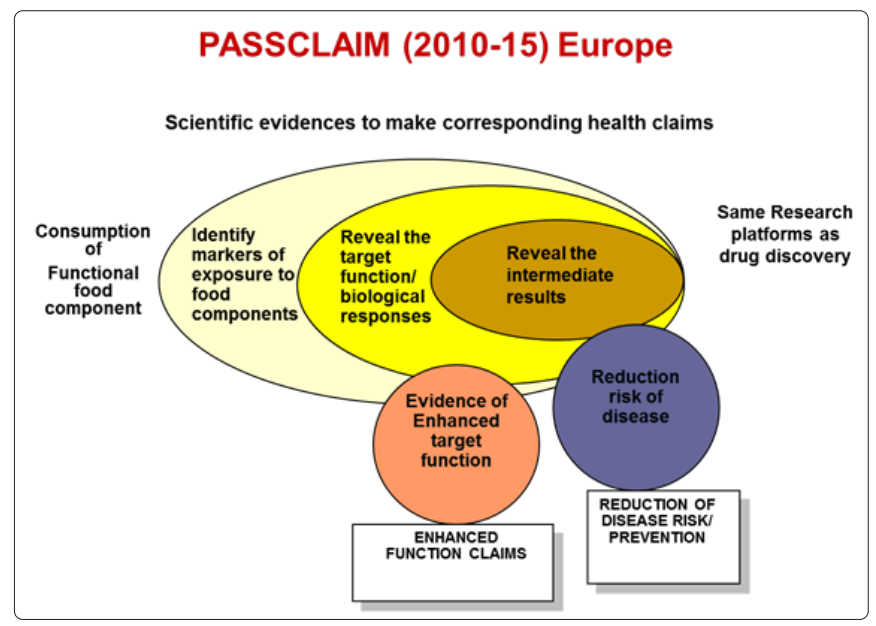

The European recommendations are well in-line with the New Directives from the China FDA. They are also in full support of what we have followed since we started to work on nutraceuticals in Hong Kong [26].

Drug discovery in the conventional route of single target intervention could be highly efficient if the pathway is straightforward, and the cost involved could be ignored. Now that we realize that single target approach could be disappointing when causative factors are complicated and multiple, the importance and practical value of nutraceuticals with proven specific medical efficacy are becoming better known. One wishes that with China's new directives, the rich resources of medicinal herbs in China and Asia, can be put under the comprehensive platforms of evidence-based exploration, to produce more and more innovative Nutraceuticals with specific medical purposes [27].

\section{References}

1. Buckwalter JA, Heckman JS, Petrice DP (2003) Aging of the North American population: New challenges for orthopaedics. J. Bone Joint. Surg 85: 748-758.

2. German PS, Fried LP (1989) Prevention and the elderly: public health issues and strategies Annu. Rev. Public Health 10: 319332.

3. Werbuch MR (1993) ed. Nutritional influences on illness. Berlin: Third Line Press; 1993: 1-43.

4. Farquhar J (1994) Knowing Practice - The Clinical Encounter of Chinese Medicine. West View Press, San Francisco.

5. Tu YY (2011) the discovery of artemisiniu and gifts from Chinese Medicine. Nature Med 17: 19-22.

6. Atsumi K (2007) Integrative approach towards "Healthy aging". In: Proceedings of "International symposium on healthy aging: harmonization of oriental medicine and western science. Tokyo: Tokyo University 2007: 2-5.

7. Cheng YC (2007) Developing Traditional Chinese Medicine into FDA - approved prescription drugs for the treatment of cancer. Phytoceutica 2007. www.phytoceutica.com/clinical program.htm.

8. Chen ST, Dou JH, Temple R, Agarwal R (2008) New Therapies from Old Medicines. Nature Biotechnology 26: 1077-1083.

9. Crutchley RD, Miller J, Garey KW (2010) Crofelemer, a Novel agent for the treatment of Secretary Diarrhea. New Drug Development 44: 878-884.

10. Medicines and Health Care Products Regulatory Agency. Phynova Joint and Muscle Relief Tablets. UKPAR-MHRATHR41783/0001.2015.

11. China FDA Announcement (2015) Food supplements with specific medical indication. CFDA 2015.

12. China FDA Announcement (2016) Food Supplements with specific medical Indications - Instructions on Production and Evaluation. CFDA 2016

13. China FDA Announcement (2017) Food Supplements with specific medical Indications - Instructions on Clinical Trials. CFDA 2017

14. China FDA Announcement (2018) Food Supplements with specific medical Indications - Priorities for babies, young mothers and elderlies. CFDA 2018

15. Leung PC, Cheng KF (2015) Clinical Trials to Evaluate Chinese Medicine. Chap 5. "A comprehensive guide to Chinese Medicine" 2nd Ed., World Scientific Publication, Singapore.

16. Leung PC Ko, E CH, Siu SWS, Pang ESY, Wong ELY, et al. (2012) Developing an effective health supplement for the prevention of osteoporosis. Intl. J. Osteoporosis Metab. Disord 5: 1-12.

17. Uppsala Monitoring Centre (2000) Safety Monitoring of Medicinal Products: Guidelines for Setting Up and Running a Pharmacovigilance Centre.

18. Leung PC, Koon CM, Lau BS, Woo KS (2014) Development of an effective Cardiovascular Protective agent using evidencebased research platform. Exp Clin Cardial 20: 4235-4248.

19. Chiu PY, Leung HY, Leong PK, Chen N, Zhou L, et al. 
(2012) Danshen-Gegen decoction protects against hypoxia/ reoxygenation-induced apoptosis by inhibiting mitochondrial permeability transition via the redox-sensitive ERK/Nrf2 and PKC e/mKATP pathways in $\mathrm{H} 9 \mathrm{c} 2$ cardiomyocytes. Phytomedicine, 2012, 19(2): 99-110.

20. Lam HM, Yam WS, Lau LK, Leung LK, Koon CM et al. Antioxidative and vasodilative effects of Danshen and Gegen. J Mol Cell Cardiol 38: 840.

21. Ng CF, Koon CM, Cheung DW, Lam MY, Leung PC, et al. (2011) The anti-hypertensive effect of Danshen (Salvia miltiorrhiza) and Gegen (Pueraria lobate) formula in rats and its underlying mechanisms of vasorelaxation. J Ethnopharmacol 137: 1366-1372.

22. Koon CM, Woo KS, Leung PC, Fung KP (2011) Salviae Miltiorrhizae Radix and Puerariae Lobatae Radix Herbal formula mediates anti-atherosclerosis by modulating key artherogenic events both in vascular smooth muscle cells and endothelial cells. J Ethnopharmacol 138: 175-183.

23. Tam WY, Chook P, Qiao M, Chan LT, Chan TY, et al. (2009) The efficacy and tolerability of adjunctive alternative herbal medicine (Salvia miltiorrhiza and Pueraria lobate) on vascular function and structure in coronary patients. J Altern Complement Med 15: 415-421.

24. Woo KS, Yip TWC, Chook P, Kwong SK, Szeto CC, et al. (2013) Cardiovascular protective effects of adjunctive alternative medicine (Salvia miltiorrhiza and Pueraria lobate) in high-risk hypertension. Evid. Based Complement Alternat Med 132912: 8 .

25. Kwok TCY, Leung PC, Lam C, Ho S, C.K. Wong, et al. (2014) A randomized placebo controlled trial of an Innovative Herbal Formula in the prevention of atherosclerosis in postmenopausal women with Borderline hypercholesterolemia. Complementary Therapies in Medicine. Complementary Therapies in Medicine.

26. Aggett PJ1, Antoine JM, Asp NG, Bellisle F, Contor L, et al. (2005) PASSCLAIM: Consensus on criteria. Eur. J Nutr 1: $15-30$.

27. Csermely P, Agoston V, Pongor S (2005) The efficiency of multi-target drugs: The network approach might help drug design. Trends Pharmacol. Sci. 26: 178-182.

Citation: Ping-Chung LEUNG (2019) China's New Directives on Nutraceuticals and Hong Kong Experience. Med Clin Res 4(3): 1-4.

Copyright: (02019 Ping-Chung LEUNG. This is an open-access article distributed under the terms of the Creative Commons Attribution License, which permits unrestricted use, distribution, and reproduction in any medium, provided the original author and source are credited. 